\title{
Review on The Production Of Concrete By Using Waste Coarse Material
}

\author{
Rajiv Sonwane ${ }^{1}$, Pushpendra Kumar Kushwaha ${ }^{2}$, Jiji M Thomas ${ }^{3}$ \\ MTech Research Scholar ${ }^{1}$, Assistant Professor ${ }^{2,3}$ \\ Department of Civil, RKDF College of Engineering, Bhopal, India ${ }^{1,2,3}$ \\ rajivsonwane8878@gmail.com,pushpendrakush1992@gmail.com
}

\begin{abstract}
Marble Industry produces large amount of waste during mining and processing stages. This waste is dumped on to open land which creates a lot of environmental problems. Similarly granite is also produced in the same manner in great amount. We get recycle aggregate from the old dumped structures and buildings. the main objective of this study was utilization of marble, granite and recycled aggregate waste with polypropylene fiber as a replacement for conventional natural coarse aggregates in concrete.
\end{abstract}

\section{INTRODUCTION}

In the modern era construction Industry is growing very enormously. Since last 3-4 decades real estate and construction companies are rising so more construction has one positive prospect in strengthening of infrastructure but on the same time there are some harmful effects also emerges. Large construction requires more materials, natural materials have limited resources and manmade materials effect our environment. Use of recycled concrete aggregate or other waste materials such as marble coarse, granite coarse and recycled coarse aggregates etc in the production of concrete for the construction of civil structures is a subject matter of significant concern. Mixing of supplementary materials in concrete and mortar affects its compressive strength, workability, and other physical and chemical properties.

There are lots of benefits by using supplementary materials in manufacturing of concrete. First benellt is the economy of construction and saving of natural materials. The other advantages of recycled materials to overcome their disposal problem. This research is obtained by replacing a considerable part of the natural aggregate by an economical, waste, industrial by-product. Second one is the reduction of natural aggregate by demolished waste materials. Following are the advantages of experiment-

(a) To reduce the quantity of deposited waste.

(b) To conserve natural resources.

Fully replacement of coarse aggregates from marble coarse, granite coarse, recycle coarse aggregates and polypropylene fiber. by utilising waste marble and granite and recycled aggregates we are saving Natural aggregates. This reduction in amount of aggregate further decreases the manufacturing cost and thus reduces the waste emissions. Present analysis allows a 100 percent replacement of Natural aggregates used in the concrete mix when replaced with a watchfully designed mixture of materials. Recycled coarse aggregates obtained from old demolish concrete structure can be effectively used in manufacturing of concrete similarly waste marble and granite obtained from industries can be used in new concrete, Many researches have

\section{LITERATURE REVIEW}

Sudarshan D. Kore, A.K. Vyas [1] Marble industry produces abundant measure of waste mining and preparing stages. This waste is dumped on (o open land which makes a considerable measure of natural issues. The fundamental target of this examination was use of marble squander as a trade of ordinary common coarse aggregates in concrete. Test examinations were done to look at the achievability of utilization of marble squander as a coarse aggregate in concrete. Customary characteristic coarse total was supplemented by marble total in various rates $\mathrm{O}$ to $100 \%$ by weight. The solid defamations were set up with a consistent 
water concrete proportion 0.60 . It was watched that workability of cement mixture containing marble was total 14 percent more than that of control concrete. The normal compressive quallty of all the solid mixture containing marble total used by $40 \%$ and $18 \%$ at 7 and 28 days individually.

Narendra Kumar Sharma, et.al [2] Disposal of solid waste materials is a great problem in cities all around the world. Some of these waste materials are not biodegradable, which often leads to disposal problems and environmental pollution. Many efforts are being made for the recycling of different types of solid wastes with a view to utilize them in the production of various construction materials in construction Industries. The granite stone Industries produces vast amount of by-product rock waste and as a result, many residential and agricultural areas are settled over the landfills which are basically composed of these waste materials. These papers reveal the use of polished granite waste from discarded tiles as a partial replacement for coarse aggregates in cement concrete. It was observed that the incorporation of polished granite waste in concrete decreases the compressive and flexural tensile while better results were observed for water absorption, abrasion and water permeability. The concrete containing polished granite waste, substituted up to $20 \%$ of natural coarse aggregate could be recommended for all applications and the substitution from $20 \%$ to $40 \%$ could be recommended for non-structural applications, pavement etc.

Sudheer Jirobe et.al. [3] they were investigated that in M25 grade of concrete the maximum compressive, and flexural strength is observed at having hybrid ratio $1.5 \%$ i.e. $0.75 \%$ steel fibber and $0.75 \%$ polypropylene fibre and when compared with conventional concrete the increase in the compressive strength with fibber addition in percentages of $0.5 \%, 1 \%, 1.5 \%$ is $10.75 \%, 27.26 \%$, $33.79 \%$ respectively. When compared with conventional concrete the increase in the split tensile strength with fibber addition in percentages of $0.5 \%, 1 \%, 1.5 \%$ is $9.22 \%, 25.09 \%, 4612 \%$ respectively. When compared with conventional concrete the increase in the flexural strength with fibre addition in percentages of $0.5 \%, 1 \%, 1.5 \%$ is $8.97 \%, 20 \%, 33.33 \%$ respectively. The maximum percentage of fibbers addition is $1.5 \%$. Fibre addition up to $1.5 \%$ gives best results in all strength parameters when compared to other mix proportions.

Antonio Andre, et.al [4] the quarrying of marble, a well-known ornamental stone, has a substantial positive impact on Portugal's economy, but it also generates large environmental impacts. The amount of waste produced during quarrying can be as much as $80 \%$ of all stone/soil extracted. That waste is then dumped near the quarry, where it accumulates indiscriminately because a. viable alternative for its disposal has not yet been found. In this context, solutions must be found that can transform this waste into a by-product and restore some of its economic value. The main goal of this study was to evaluate the influence of the replacement of primary

\section{METHODOLOGY}

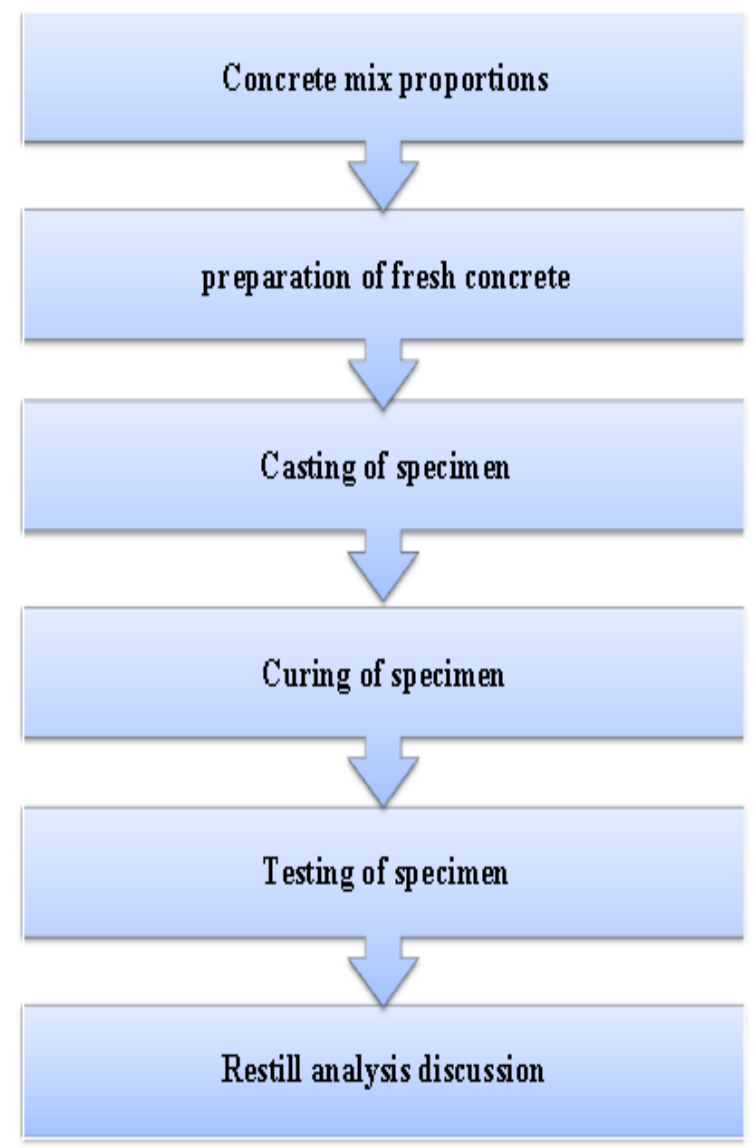

Figure 1 Flow Chart of Methodology 


\section{MARBLE}

Marble is the metamorphic rock that develops form limestone. Most of the material likes calcite (a crystalline form of calcium carbonate, $\mathrm{CaCO} 3$ ) and dolomite. It is often used for sculpture, as a building material, and for many other purposes. Marble has been used in construction for Thousands of years. Marble is a metamorphic rock composed of recrystallized carbonate minerals, most commonly calcite or dolomite. Marble may be foliated. Geologists use the term "marble" to refer to metamorphosed limestone; however, stonemasons use the term more broadly to encompass metamorphosed limestone. Marble is commonly used for sculpture and as a building material.

\section{POLYPROPYLENE FIBER}

Polypropylene fiber concrete is flexible and might be employed in most applications. Plastic fibre is additional to the concrete throughout batching.

The capability of sturdy structure to resist Weathering action, chemical attack, abrasion and different degradation processes throughout its service life with the nominal maintenance is equally vital because the capability of a structure to resist the masses applied thereon.

Though concrete offers several benefits relating to mechanical characteristics and economic aspects of the development, the brittle behavior of the fabric remains a bigger handicap for the seismic and different applications wherever versatile behavior is actually needed.

Recently, but the event of plastic fiber-reinforced concrete (pfrc) has provided a technical basis for up these deficiencies. this paper presents an summary of the impact of plastic ( $\mathrm{pp}$ ) fibbers on numerous properties of concrete in contemporary and hardened state like compressive strength, lastingness, flexural strength, workability, bond strength, fracture properties, creep strain, impact and chloride penetration.

\section{CONCLUSION}

In the present study, the use of waste materials in concrete was reviewed. The intention of this study was to express the advantages and disadvantages of using waste in concrete, the effect of doing this and introducing materials that can be used in concrete.
In order to clarify the details, the reviews were conducted in two parts, considering substitutes as aggregates and substitutes as part of cement.

\section{REFERENCES}

[1] SD kore. a.k.vyas "Impact of marble waste as coarse aggregate on properties of lean cement concrete" ,Construction material ,2016

[2] Narendra Kumar Sharma , Praveen Kumar , sanjeev Kumar, balessen skariah Thomas, ramesh Chandra gupta "Property of concrete containing polished granite waste as partial substitution of coarse aggregate" Construction and building material ,Volumel51, 2017.

[3] S Varghese et.al "Recycle plastic as coarse aggregate for structure "International journal of Innovative.2013.

[4] Antonia andre, Jorge de brito, Alexandra rosa, Diogo pedro "Durability performance of concrete incorporating coarse aggregate from marble industry waste", Journal of cleaner production, volume 65, Feb 2014.

[5] Allabdo All A., Elmoaty Abd, Elmoaty M. Abd, Esraa M. Auda "Re-use of waste marble dust in the production of cement and concrete". Construction and Building Materials, Volume 50, 15 January 2014, Pages 28-41, ISSN 0950-061.

[6] Anna Kotwa "The replacement of the parts of the aggregate in concrete with Chalcedonite powder- Procedia Engineering ,Volume 195, 2017.

[7] Antonia andre, Jorge de brito, Alexandra rosa, Diogo pedro "Durability performance of concrete incorporating coarse aggregate from marble industry waste", Journal of cleaner production, volume 65, Feb 2014.

[8] Bashar S. Mohammed, M. Abudullahi ,C.K. Hoong " Statistical models for concrete containing wood chipping as partial replacement to fine aggregate" Construction and Building Material, volume 55, 2014. 